\title{
Immunohistochemistry versus traditional myofibrillar ATPase histochemistry for identification of muscle fibre types in horses
}

\author{
J. L. L. Rivero \\ Anatomy and Embryology Unit; Department of Comparative Anatomy and Pathological Anatomy, Faculty of Veterinary Science, University of Cordoba, Cordoba, Spain
}

\begin{abstract}
Summary
Five young (2- to 3 -years old) thoroughbred horses were intensively trained for 8 months on a high-speed treadmill. Biopsies were taken from the gluteus medius muscle at the beginning, after 4 months, and again at the end of the training programme. Serial sections of the samples were stained by myofibrillar ATPase (mATPase) histochemistry and immunohistochemistry using a number of monoclonal antibodies specific to selected myosin heavy chain (MyHC) isoforms. The histochemical and immunohistochemical categorization of a large number of fibres $(\mathrm{N}=2,078)$ was compared fibre by fibre. A high proportion of fibres examined $(\sim 20 \%)$ were mis-classified by traditional mATPase histochemistry. Many fibres histochemically identified as type IIB displayed both type lla and type IIb MyHc isoforms, and nearly all type IIAB fibres in mATPase contained only the type lla MyHC isoform by immunohistochemistry. Training had no significant effect on the number of fibres mis-classified by mATPase histochemistry. These data demonstrate a significant limitation in the mATPase histochemistry for assessing fibres containing fast $\mathrm{MyHC}$ isoforms.
\end{abstract}

Keywords: $\quad$ skeletal muscle, monoclonal antibody, muscle fiber, horse

\begin{abstract}
Vergleich von immunohistochemischer und traditioneller myofibrillärer ATPase-histochemischer Nachweismethode zur Identifikation von Muskelfasern beim Pferd

Fünf Vollblutpferde, im Alter von 2 bis 3 Jahren, wurden auf einem Hochgeschwindigkeitslaufband 8 Monate lang intensiv trainiert. Zu Beginn des Trainings, nach 4 Monaten und am Ende der Trainingsperiode wurden Muskelbiopsien aus dem M. glutaeus medius aus einer Tiefe von $2 \mathrm{~cm}$ entnommen. In jedem Bioptat wurden die Muskelfasern anhand histochemischer und immunohistochemischer Methoden identifiziert. Dazu wurden zunächst von jedem Bioptat mehrere Schnitte angefertigt. Diese Schnitte wurden bei der histochemischen Identifikationsmethode angefärbt, um die Aktivität der myofibrillären Adenosin-Triphosphatase (mATPase) bei verschiedenen pH-Werten nachzuweisen. Bei der immunohistochemischen Methode wurden verschiedene monoklonale Antikörper auf die Schnitte aufgetragen, anhand derer verschiedene Isoformen der schweren Myosinkette (MyHC) nachgewiesen werden. Die histochemische und immunohistochemische Klassifizierung einer großen Anzahl Fasern ( $n=2.078$ ) wurde Faser für Faser verglichen. Ein großer Anteil der untersuchten Fasern (ca. 20\%) wurde anhand der traditionellen mATPase-Histochemie falsch klassifiziert. Viele Fasern, die histochemisch als Typ IIB klassifiziert wurden, wiesen die MyHC-Isoformen von sowohl Typ Ila- als auch von Typ Ilb-Fasern auf. Fast alle histochemisch als Typ IIAB eingestufte Fasern enthielten laut immunohistochemischer Identifikation nur die MyHC-Isoformen der Typ Ila-Fasern. Der Anteil der mittels der mATPase-Histochemie falsch klassifizierten Fasern wurde durch das Training nicht signifikant beeinflußt. Diese Ergebnisse zeigen den begrenzten Aussagewert der mATPase-Histochemie bei der Bestimmung von Muskelfasern, in denen gleichzeitig MyHC-Isoformen vorkommen.
\end{abstract}

Schlüsselwörter: Skelettmuskel, monoklonale Antikörper, Muskelfaser, Pferd

\section{Introduction}

In horses, muscle fibres have been routinely categorized into three major types, designated types I, IIA and IIB, and the minor IIC, based upon the myofibrillar actomyosin adenosine triphosphatase (mATPase) histochemical reaction proposed by Brooke and Kaiser (1970). Using immunohistochemical methods, it has been suggested that the histochemical staining intensity of the mATPase reaction in a given muscle fibre is determined by its myosin heavy chain (MyHC) content (Billeter et al., 1981). In a companion study (Rivero et al. 1995), we have identified one slow- and two fast- (Ila, and IIx or Ilb) MyHC isoforms in the adult equine skeletal muscle by using monoclonal antibodies and gel electrophoresis techniques.

Although a direct correlation between the histochemical reactivity for mATPase and the MyHC content of a given fibre has been established (Staron and Pette, 1986), the disadvantages of the mATPase technique have recently been highlighted in humans (Klitgaard et al. 1990; Andersen et al., 1994). These studies suggest that many fibres histochemically classified as type I or type IIB contain to some degree the fast Ila-MyHC, particularly in trained muscles. Moreover, the coexpression of multiple $\mathrm{MyHC}$ isoforms within a single fibre also occurs under normal conditions (Biral et al., 1988). In summary, as the dominant $\mathrm{MyHC}$ isoform determines the histochemical mATPase reaction of a fibre (Danielli-Beto et al., 1986), this method does not reveal subtle alterations in the expression of $\mathrm{MyHCs}$ in muscle fibres and, therefore, may not adequately characterize muscle fibre distribution in control or in trained horses. The main purpose of the present investigation was to ascertain the degree of association between the $\mathrm{MyHC}$ content of muscle fibres and histochemical muscle fibre type distribution by combining classical qualitative mATPase histochemistry and immunohistochemical analyses of $\mathrm{MyHC}$. 


\section{Materials and methods}

Six clinically healthy thoroughbred racehorses (5 mares and one gelding) were used in this study. Two horses were 3 years old and the other four were 2 years old at the beginning of the study.

Five of the horses were included in a training programme aimed at investigating the influence of intensity and duration of exercise on several physiological variables. The sixth horse was used as a control in order to evaluate changes associated with age. All the exercise workouts and standardized tests were done on a highspeed treadmill (Mustang 2200 ${ }^{\circledR}$, Kagra SA. Fahrwangen, Switzerland). The experimental period was extended for about 8 months. After a one-month acclimatization period, all 5 trained horses carried out 6 phases of exercise, varying in intensity and duration of exercise. Each phase consisted of 11 exercise workouts (once a day every second day), so each phase was extended for 21 days. Between two consecutive phases, horses were allowed to rest for one week. In this week, a standardized exercise test (SET) was performed for each horse in order to determine VLA2.5 and VLA4, or speeds which run over a defined period of time produce a concentration of lactate in blood of 2.5 and 4 $\mathrm{mmol} / \mathrm{l}$, respectively (Lindner et al., 1992). This was the parameter on which the intensity of exercise made in each phase of training was based. Of the 6 phases of training, 3 were made at an intensity of work of VLA2.5 and the other 3 in VLA4. In both sets of these phases the duration of each exercise session was 5,15 or 25 minutes.

Muscle biopsies (75-150 mg) were obtained from the right gluteus medius muscle (depth: $2 \mathrm{~cm}$ ) of each horse according to Lindholm and Piehl (1974). Biopsies were taken before, after 4 months of training, and again at the end of the 8-month training programme. Control horse biopsies were taken at the same time periods. After collection, muscle samples were frozen and stored as described elsewhere (Rivero et al., 1995, companion paper).

Frozen biopsy samples were thawed to $-20^{\circ} \mathrm{C}$ in a cryostat and serially sectioned for histochemistry (using $10 \mu \mathrm{m}$ thick sections placed on cover slips) and immunohistochemistry (using $10 \mu \mathrm{m}$ thick sections placed on gelatin coated slides)

Serial cross-sections were stained qualitatively for the demonstration of myofibrillar adenosine triphosphatase (mATPase) activity after alkaline $(\mathrm{pH} 8.75)$ and acid ( $\mathrm{pH} .4 .2$ and $\mathrm{pH} 4.5)$ preincubation using a modification (Nwoye et al., 1982) of the Brooke and Kaiser (1970) method.

Serial sections were reacted with 4 different monoclonal antibodies specific to rat $\mathrm{MyHC}$ isoforms. Individual cross-sections were labeled for Slow, Fast, A4.74 and N2.261 monoclonal antibodies. The source and specificity of these monoclonal antibodies, as well as the immunohistochemical procedure employed, are described in the companion paper (Rivero et al., 1995).

A region of the cross sections containing between 100 and 135 fibres per muscle biopsy was randomly selected for further analysis. These fibres were numbered and classified at random using histochemical and immunohistochemical methods. Myofibres were classified into types I, ॥C, IIA, IAB and IIB (Brooke and Kaiser, 1970; White and Snow 1985) according to the mATPase staining characteristics at the different levels of preincubation acidity. The same fibres were allotted to types I, I+\|A, IIA, IIA+\|B (or $\|A+\| X$ ), and IIB (or IIX) according to their MyHC content as revealed by reactivity against monoclonal antibodies (see companion paper Rivero et al., 1995). To compare histochemical vs. immunohistochemical data, these five fibre types were also renamed as types I, IIC, $\|A\| A$,$B , and \| B$, respectively. The fibre type distri-

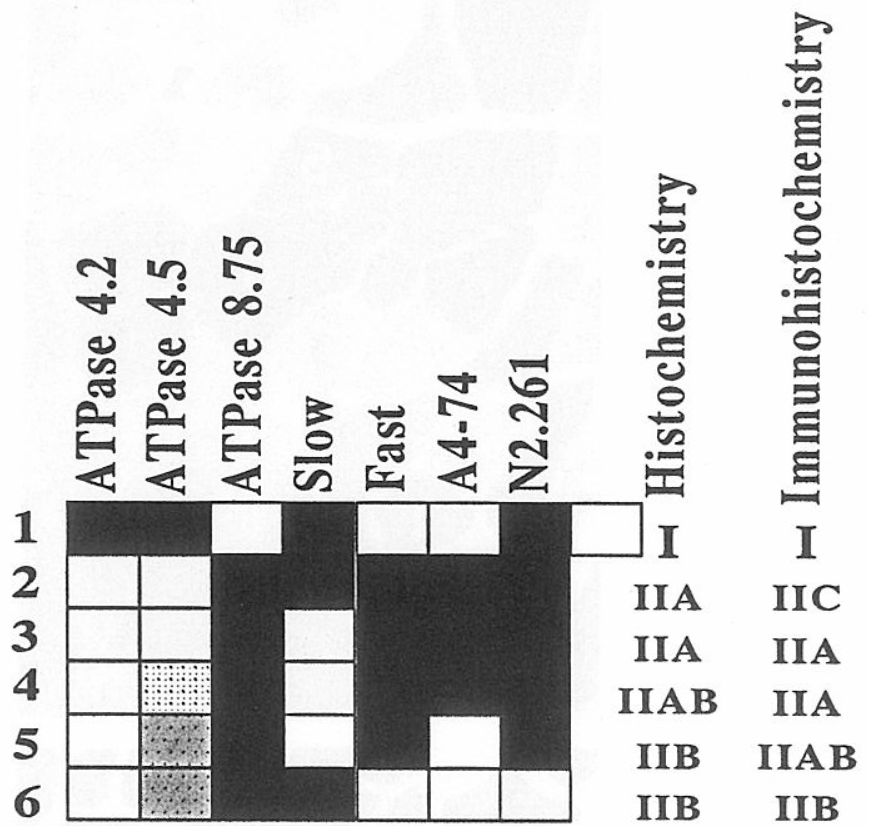

Fig. 1: Scheme showing the patterns of reactivity of the six most common fiber types identified by histochemistry and immunohistochemistry. These six fibre types are labelled in Fig. 2.

bution of each muscle biopsy was established by counting and typing the relative frequency of the various fibre types in each sample.

One-way analysis of variance (ANOVA) with repeated measurements was used to determine whether significant effects of training existed.

\section{Results}

Fig. 1 illustrates a scheme showing the pattern of reactivity of the six most common fibre types identified by histochemistry and immunohistochemistry. Based on histochemical analysis (mATPase reaction) the muscle fibres could be divided into five categories: I, $\| C$ (not shown), $\|\mathrm{A},\| \mathrm{AB}$, and $\| \mathrm{B}$ (Fig. 2A). A continuum in the staining intensity for mATPase after acid preincubation $(\mathrm{pH} 4.5)$ was observed between the type IIA and type IIB fibre population (Fig. 2A). All these fibres were identified as type IIAB. Five different fibre populations were also demonstrated immunohistochemically using specific monoclonal antibodies (Fig. 2B-D). Fibres that reacted exclusively with the Slow MyHC antibody were termed I. Fibres that were unreactive with the Slow MyHC antibody and reacted with Fast, A4.74, and N2.261 antibodies were called IIA, and those fibres that did not react with all monoclonal antibodies except the Fast MyHC antibody were called IIB. Two subgroups of fibres co-expressing two different MyHCs were also identified, and these were designed as IIC (fibres coexpressing types I and Ila MyHCs), and IIAB (fibres co-expressing both fast MyHCs).

Combined histochemical and immunohistochemical analyses demonstrated a certain degree of correlation, albeit not unequivocal, between mATPase staining intensities and myosin heavy chain (MyHC) content. Type I fibres were histochemically uniform and reacted with the Slow, A4.74, and N2.261 (e.g. fibres labeled ' 1 ' in Fig. 2). However, the fast-twitch fibre population was histochemically and immunohistochemically heteroge- 

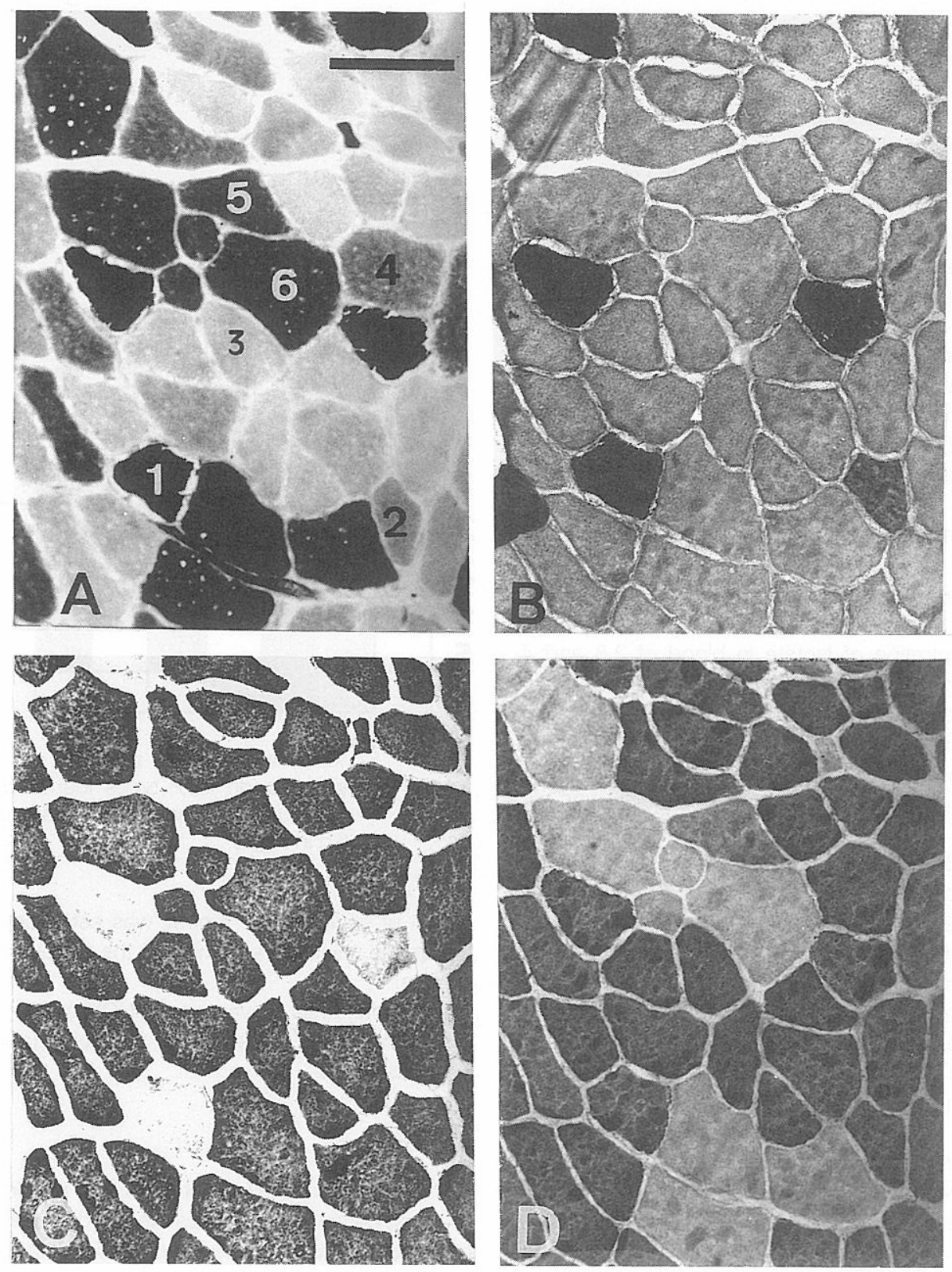

Fig. 2. Identification of fibre types by enzyme histochemistry and immunohistochemistry. A) Myosin ATPase after preincubations at $\mathrm{pH}$ 4.5. Immunohistochemical staining with monoclonal antibodies Slow (A), Fast (B) and N2.261 (C). The fibres labelled '1' to '6' correspond to those fibres illustrated in Fig. 1. Scale bar $=100 \mu \mathrm{m}$.

neous. Most fibres histochemically classified as IIA contained only Ila $\mathrm{MyHC}$ (e.g. fibre labeled ' 3 ' in Fig. 2). Similarly, a high percentage of fibres histochemically classified as IIB contained a mixture of Ila and IIb MyHCs ( 24\% of IIB mATPase fibres), and were classified as type IIAB by immunohistochemistry (e.g. fibre labeled ' 5 ' in Fig. 2). Those fibres which stained intermediately between IIA and IIB mATPase fibres (type IIAB) had frequently a mixture of $\mathrm{lla}$ and Ilb MyHCs, but a high proportion of these hybrid fibres for mATPase were exclusively composed of Ila MyHC ( 61\%), so they were classified as Ila by immunohistochemistry (e.g. fibre labeled '4' in Fig. 1). Finally, some fibres stained more like IIC fibres by histochemistry contained only the slow-MyHC (not shown); conversely, a few fibres co-expressing both the slow- and the fast Ila-MyHCs were typed as I for mATPase (e.g. fibre labelled ' 2 ' in Fig. 2).
Almost no significant changes $(P>0.05)$ in fibre type composition was recorded as a consequence of training (Tab. 1). Training had no significant effect on the number of muscle fibres mis-classified by qualitative mATPase activity in correspondence with their $\mathrm{MyHC}$ content revealed by immunohistochemistry (Tab. 2).

\section{Discussion}

Comparison between the histochemical and immunohistochemical data shows that $\sim 20 \%$ of the fibres were misclassified by traditional mATPase histochemistry. Each MyHC isoform can be associated rather consistently with a specific mATPase-based muscle fibre type (Staron and Pette, 1986), except when two or more MyHCs coexist within the same fibre. It has been suggested that fibres coexpressing two or more MyHC isoforms will his- 
Tab. 1: Percentage of the various fibre types identified immunohistochemically and by qualitative myosin ATPase of 5 horses (Training) and one control horse (Control) along the experimental period

\begin{tabular}{|c|c|c|c|c|c|c|}
\hline \multicolumn{4}{|c|}{ Immunohistochemistry } & \multicolumn{3}{|c|}{ Histochemistry } \\
\hline Month & 0 & 4 & 8 & 0 & 4 & 8 \\
\hline $\begin{array}{l}\text { Training }(\mathrm{N}=5) \\
\text { IAA } \\
\text { IIAB } \\
\text { IIB }\end{array}$ & $\begin{array}{cl}13.2 & (4.2) \\
42 & (7) \\
9 & (3.8) \\
35.8 & (4.8) \\
\end{array}$ & $\begin{array}{r}8.6(6.1) \\
43.2(7.2) \\
13.4(4.2) \\
34.8(5.4) \\
\end{array}$ & $\begin{array}{l}13.8(11.4) \\
40.8(13.7) \\
11.8(3.7) \\
33.6(11.5)\end{array}$ & $\begin{array}{l}13.2(4.2) \\
34.4(8.5) \\
10.2(2.2) \\
42.2(6.4)\end{array}$ & $\begin{array}{l}8.6(6.1) \\
34.6(5.3) \\
15 \quad(4.2) \\
41.8(4)\end{array}$ & $\begin{array}{r}13.8(11.4) \\
34.2(10.2) \\
6.2(1.5)^{\star} \\
45.8(8.2)\end{array}$ \\
\hline $\begin{array}{l}\text { Control }(\mathrm{N}=1) \\
\text { I } \\
\text { IIA } \\
\text { IIAB } \\
\text { IIB }\end{array}$ & $\begin{array}{l}12 \\
38 \\
15 \\
35\end{array}$ & $\begin{array}{r}7 \\
42 \\
16 \\
35\end{array}$ & $\begin{array}{r}5 \\
35 \\
27 \\
33\end{array}$ & $\begin{array}{r}12 \\
32 \\
8 \\
48\end{array}$ & $\begin{array}{r}7 \\
34 \\
12 \\
47\end{array}$ & $\begin{array}{r}5 \\
27 \\
23 \\
45\end{array}$ \\
\hline
\end{tabular}

Values are mean (SD). N = number of horses. * Significantly different from second muscle biopsy $(P<0.001)$. No significant $(P>0.05)$ variations along the experimental period were found for the other muscle parameters

Tab. 2: Number and percent of muscle fibres mis-classified by qualitatitive mATPAse histochemistry in comparison with immunohistochemistry in all the 18 muscle biopsies examined

\begin{tabular}{|c|c|c|c|c|c|c|}
\hline \multicolumn{7}{|c|}{ Month } \\
\hline $\begin{array}{l}\text { Immunohisto- } \\
\text { chemistry }\end{array}$ & Histochemistry & 0 & 4 & 8 & Total & Percent \\
\hline $\begin{array}{l}\| A B \\
\| A B \\
\| A \\
\| B \\
\| A \\
\| B \\
\text { I }\end{array}$ & $\begin{array}{l}\| A \\
\| B \\
\| A B \\
\| A B \\
\| B \\
\| A \\
\| C\end{array}$ & $\begin{array}{c}(\mathrm{N}=684) \\
3 \\
49 \\
46 \\
3 \\
10 \\
2 \\
3\end{array}$ & $\begin{array}{c}(\mathrm{N}=698) \\
8 \\
59 \\
65 \\
5 \\
3 \\
1 \\
0\end{array}$ & $\begin{array}{c}(\mathrm{N}=696) \\
5 \\
65 \\
49 \\
3 \\
4 \\
0 \\
0\end{array}$ & $\begin{array}{l}(\mathrm{N}=2,078) \\
16 \\
173 \\
160 \\
11 \\
17 \\
3 \\
3\end{array}$ & $\begin{array}{r}4 \\
45 \\
42 \\
3 \\
4 \\
1 \\
1\end{array}$ \\
\hline Total & & 116 & 141 & 126 & 383 & \\
\hline Percent & & 17 & 20 & 18 & 18.5 & \\
\hline
\end{tabular}

$\mathrm{N}=$ number of fibres examined

tochemically react according to the dominant isoform (Klitgaard et al., 1990). The finding that many fibres histochemically classified as type IIB coexpressed Ila and IIb MyHCs supports this assumption. Further some fibres histochemically identified as type I, coexpressed type I and type Ila MyHCs based on immunohistochemistry. On the other hand, nearly all fibres histochemically classified as type IIAB contained only lla MyHC.

The observation that a large number of histochemically determined IIB fibres actually contain a varying amount of type Ila $\mathrm{MyHC}$ is in agreement with previous studies on human single fibres (Andersen et al., 1994). In this study, it was reported that nearly all histochemical type IIB fibres of sprinters (Andersen et al., 1994) coexpressed both Ila and IIb MyHC isoforms. The explanation for the finding that practically all histochemically typed IIAB fibres contained only Ila MyHC is unclear. It may be speculated that the mATPase histochemical staining is affected by factors other than the relative content of $\mathrm{MyHC}$. The results of a former study of the mATPase activity of equine muscle fibre types by quantitative histochemistry (White and Snow, 1985), clearly showed a continuous range within the type II fibres with the two or three overlapping peaks. As this continuum of fibre types is difficult to quantify using a qualitative technique such as mATPase histochemistry, this method of classification of muscle fibres into four major types (5 if the type IIC are included) may have major limitations in objectively differentiating among the 3 fast subtypes
(IIA, IIAB, IIB) based on MyHC content. Our observation of some fibres histochemically identified as type I, but coexpressing both I and Ila MyHC is similar to reported for human muscle (Klitgaard et al. 1990). Klitgaard et al. (1990) reported that in the $95 \%$ of fibres in endurance athletes that contained both I and Ila MyHCs the major fraction was the type I MyHC, perhaps explaining the histochemical staining profile of a type I fibre.

Another striking observation of the present study was that training had no significant effect on the correlation between mATPase activity and $\mathrm{MyHC}$ content of muscle fibres. In some studies, it has been argued that the 'mis-classification' of many fibres by mATPase histochemistry seems to be especially pronounced in trained individuals, because of the presence of a high number of fibres coexpressing multiple MyHCs (Klitgaard et al., 1990).

Surprisingly, no significant changes in muscle fibre type composition were observed in the current study after 4 and 8 months of training. In horses, as in humans and other mammals, the most common adaptation to training is an increase of the type IIA to type IIB histochemical fibre ratio, and an increase of both the oxidative capacity and capillary supply of muscle fibres (see Snow and Valberg, 1994 for a review). As the intensity and duration (both daily and in total) of exercise involved in the current study was higher than other previous studies in horses (Snow and Valberg, 1994), the limited training-related changes in muscle fibre type characteristics recorded in our study is difficult to explain. It 
may be, however, linked to the relatively superficial sampling site of the gluteus medius muscle from which the samples were taken. In a recent study (Rivero et al., 1995), it was found that the adaptation of the gluteus medius muscle fibres to training was not homogeneous in superficial and deep sampling regions of this muscle. As these training-linked modifications were more marked in the deep region of the muscle compared with the superficial one, it was concluded that different functional demands are placed on different depths of the gluteus medius muscle. This lack of muscular response to training may also be partially explained because no real metabolic adaptation occurred in response to training, in spite of the relative intensity of the training being individually adjusted to each horse. On the other hand, the performance capacity of each individual horse did not improve throughout the training programme, as was shown by the constant values of VLA4 (Lindner, personal communication).

In conclusion, histochemical and immunohistochemical techniques applied to equine skeletal muscle establish a relationship between qualitative myofibrillar mATPase activity and MyHC content. However, a high percentage of fibres of the equine gluteus medius muscle are mis-classified by traditional mATPase histochemistry, since it does not adequately identify the hybrid fibre population coexpressing the two fast $\mathrm{MyHC}$ isoforms. Therefore, and despite the extensive use of mATPase histochemistry to distinguish skeletal muscle fibre types in horses, the present results do no support the use of this qualitative technique. The use of monoclonal antibodies against specific MyHCs seems to be a more sensitive, more reproducible and less subjective method for that purpose.

\section{Acknowledgements}

This study was completed while José-Luis L. Rivero was working at the Department of Physiological Sciences, University of California at Los Angeles, USA, supported by grants and scholarships from the Spanish D.G.C.Y.T. (Ref: PR94-202) and the University of Cordoba, Spain.

\section{References}

Andersen, J. L., Klitgaard, H. and Saltin, B. (1994): Myosin heavy chain isoforms in single fibres from $\mathrm{m}$. vastus lateralis of sprinters: influence of training. Acta Physiol. Scand. 151: 135-142.

Billeter, R., Heizmann, C. W., Howard, H. and Jenny, E. (1981): Analysis of myosin light and heavy chain types in single human skeletal muscle fibres. Eur. J. Biochem. 116: 389-395.
Biral, D., Betto, R., Betto, D. D. and Salviati, G. (1988): Myosin heavy chain composition of single fibres from normal human muscle. Biochem. J. 250: 307-308.

Brooke, M. M. and Kaiser, K. K. (1970) Muscle fibre types: how many and what kind?. Arch. Neurol. 23: 369-379.

Danieli-Betto, D., Zerbato, E. and Betto, R. (1986) Type 1, 2A and 2B myosin heavy chain electrophoretic analysis of rat muscle fibres. Biochem. Biophys. Res. Comm. 138: 981.

Klitgaard, H., Bergman, O., Betto, R., Salviati, G., Schiaffino, S., Clausen, R. and Saltin, B. (1990): Co-existance of myosin heavy chain I and Ila isoforms in human skeletal muscle fibres with endurance training. Plügers Archiv. 416: 470-472.

Lindner, A., von Wittke, P., Schmald, M., Kusserov, J. and Sommer, $H$. (1992): Maximal lactate concentrations in horses after exercise of different duration and intensity. J. Equine Vet. Sci. 12: 30-33.

Lindholm, A. and Piehl, K. (1974): Fibre composition, enzyme activity and concentration of metabolites and electrolytes in muscles of Standardbred horses. Acta Vet. Scand. 15: 287-309.

Nwoye, L., Mommaerts, W. F. H. M., Simpson, D. R., Serayderian, K. and Marusich, M. (1982): Evidence for a direct action of thyroid hormone in specifying muscle properties. Am. J. Physiol. 242: R401-408.

Pette, C. and Staron, S. (1990): Cellular and molecular diversities of mammalian skeletal muscle fibres. Rev. Physiol. Biochem. Pharmacol. 116: 1-76.

Rivero, J. L. L. (1995) Fast myosin heavy chain isoforms in horse skeletal muscle: an immunohistochemical and electrophoretic study. (companion paper).

Rivero, J. L. L., Ruz, M. C., Serrano, A. L. and Diz, A. M. (1995): Effects of a 3 month endurance training programme on skeletal muscle histochemistry in Andalusian, Arabian and Anglo-Arabian horses. Equine Vet. J. 27: 51-59.

Snow, D.H. and Valberg, S. J. (1994): Muscle anatomy, physiology and adaptations to exercise and training. In: The athletic horse. D. R. Hodgson and R. J. Rose. WB Saunders, Philadelphia. pp. 145-179.

White, M. G. and Snow, D. H. (1985): Quantitative histochemistry of myosin ATPase activity after acid preincubation, and succinate dehydrogenase activity in equine skeletal muscle. Acta Histochem. Cytochem. 18: 483-493.

\section{Dr. José Luis López Rivero}

Departamento de Anatomía

Facultad de Veterinaria

Universidad de Córdoba

Medina Azahara 9, 14005 Córdoba, Spain

Fax: + 34572186 66; Phone: +34 57218675

E-mail: an1lorij@/ucano.uco.es 